\title{
COMERCIO JUSTO, TIPOLOGÍA DE ACTORES Y PRÁCTICAS COMERCIALES CONTROVERTIDAS
}

\author{
Gabriela PARODI ${ }^{1}$
}

\section{Resumen}

El artículo retoma el análisis tipológico del Comercio justo propuesto en la literatura francesa, para comprender el desarrollo y fundamentos de una práctica controvertida entre promotores y consumidores franceses: la comercialización de productos en los supermercados. La región de Loire-Atlantique, al noroeste de Francia, fue el área de estudio de la tesis doctoral en sociología. A partir de entrevistas en profundidad, analizamos cómo la estructuración del sistema se explica en gran parte por el carácter ideologizado de aquella práctica condicionando las relaciones de fuerza de los actores y la legitimidad de las formas de comercialización y de consumo reivindicadas.

Palabras claves: Comercio justo, tipología, comercialización, legitimidad, relaciones de fuerza.

\section{Résumé}

L'article reprend l'analyse typologique du Commerce équitable proposée dans la littérature française, pour comprendre le développement et les fondements d'une pratique controversée parmi les promoteurs et consommateurs français : la commercialisation des produits dans les supermarchés. Au nord-ouest de la France, la Loire-Atlantique a été la région d'étude de la thèse doctorale en sociologie. À partir des entretiens approfondis, nous avons analysé comment la structuration du système s'explique en grande partie par le caractère idéologisé de cette pratique, en conditionnant les relations de force des acteurs et la légitimité des formes de commercialisation et de consommation revendiquées.

Mots-clés: Commerce équitable, typologie, commercialisation, légitimité, rapports de force.

\begin{abstract}
\footnotetext{
${ }^{1}$ Becaria Postdoctoral CEIL-CONICET

Centro de Estudios e Investigaciones Laborales (CEIL)

Saavedra 15 , Piso $4^{\circ}$, C1083ACA, Ciudad de Buenos Aires

Correo: gabrielaparodi6@gmail.com
}

The article follows the typological analysis of the Fair trade proposed in the French literature, to understand the development and foundations of a controversial practice between French promoters and consumers: the commercialization of products in the supermarkets. LoireAtlantique's region, in the northwest of France, was the area of study of the doctoral thesis in

Fecha de recepción del artículo:Abril 2015

Fecha de evaluación: Junio 2015 
sociology. From interviews in depth, we analyze how the structure of the system explains largely the ideological character of that practice determining the forces-relationship of the actors and the legitimacy of the forms of commercialization and of consumption claimed.

Key-words: Fair trade, typology, commercialization, legitimacy, forces-relationship.

\section{Introducción}

El comercio justo (CJ), como forma de comercialización de productos a escala internacional, tiene por fundamento revalorizar la relación de intercambio Norte-Sur a partir de la inclusión de pequeñas unidades productivas en el mercado mundial de materias primas. Si bien su objetivo es favorecer la equidad en las relaciones comerciales, no todas las prácticas de comercialización son compartidas por los actores del movimiento. La evolución y configuración de los circuitos de venta de estos productos en los países del Norte, y en particular en Francia, tuvo como correlato el surgimiento de posiciones encontradas entre los actores que participan de este comercio a propósito de la legitimidad acordada a las formas de comercialización practicadas, dando lugar a controversias.

La venta de productos certificados CJ por medio de la gran distribución es una de las formas de comercialización analizada en nuestra tesis doctoral (Parodi 2011) sobre el consumo de productos del CJ en Francia, al noroeste del país, específicamente en la región de LoireAtlantique. La controversia surgida en torno de esta práctica fue observada, tanto a nivel de sus promotores como de los consumidores franceses entrevistados, identificando por un lado, los partidarios de este tipo de comercialización y, por el otro, los refractarios. A través de su análisis pudimos estudiar no sólo los fundamentos de ambas posturas sobre el circuito de comercialización genuino para ejercer la venta de este tipo de productos sino, por extensión, los del sistema del CJ en general que dan origen a la coexistencia de circuitos comerciales y redes asociativas paralelos al interior del propio movimiento.

El artículo aborda el entramado complejo de prácticas y relaciones comerciales que describen al CJ para comprender la(s) lógica(s) subyacentes al mismo, desde una perspectiva teórica y empírica. A nivel teórico, retomamos la caracterización tipológica de la estructura socioeconómica y dinámica del movimiento a nivel mundial, siguiendo tres enfoques. La primera tipología, que denominamos "simplificada", resulta de un estudio-expertise realizado por un grupo de centros de investigación y organismos no gubernamentales, en su mayoría franceses ${ }^{2}$. La segunda tipología, por sectores, surge del análisis de Ronan Le Velly, sociólogo francés, basado en los postulados de la Nueva sociología económica. La tercera tipología, por polos, retoma el aporte de Philippe Robert-Demontrond desarrollado desde la perspectiva en ciencias de la gestión. Dentro del análisis tipológico de los actores del CJ presentamos la experiencia de la Fundación Fortalecer, institución de la Federación Agraria Argentina (FAA), actor inserto en uno de los circuitos de comercialización preponderantes del sistema, el de la certificación internacional. Ella forma parte del estudio de casos analizados en el marco de una investigación postdoctoral actual sobre Agricultura familiar y $\mathrm{CJ}^{3}$. A nivel empírico, movilizamos los resultados del trabajo de campo realizado entre 2003 y 2010, donde fueron observadas y analizadas las prácticas de promoción y consumo del CJ y realizadas entrevistas en profundidad a promotores y consumidores franceses, así como a productores de café peruanos

2 La asociación francesa 1901 Solidarités Agricoles et Alimentaires (Solidaridades Agrícolas y Alimentarias) realizó el estudio en asociación con el CIRAD (Centre de coopération internationale en recherche agronomique pour le développement), CICDA (Centre international de coopération pour le développement agricole) y CEDAC (Centre d'études et d'action pour la cohésion sociale) de Bélgica.

3 "Beca Interna Postdoctoral de Reinserción", CONICET (2013-2015), con sede en el Centro de Estudios e Investigaciones Laborales (CEIL). Director: Guillermo Neiman. Co-directora: Silvia Gorenstein. 
entrevistados en Francia (invitados durante las campañas de promoción) y en Perú (en la zona de producción de la región de Cajamarca).

A través de ambas perspectivas de análisis, teórica y práctica, buscamos poner de relieve la dimensión compleja y hasta conflictiva que conlleva definir al CJ como sistema comercial y como movimiento social por parte de sus actores que no reconocen de manera homogénea, según tal o cual práctica, el compromiso y la legitimidad atribuidos a este comercio, más allá de las especificidades del caso francés.

\section{El movimiento del Comercio Justo, caracterización tipológica}

Al movimiento del CJ se lo suele presentar en la literatura científica y no científica (DiazPedregal 2007:15-16) de forma esquematizada, desarrollando tipologías con diferentes grados de complejidad para describir el tipo de filiación de los actores involucrados en el sistema.

Podemos identificar tipologías del CJ por sectores o, aún más complejas, por polos. El denominador común en ellas es el entramado complejo de relaciones de fuerza que alcanza a los actores del movimiento no sólo en términos ideológicos sino también en términos de prácticas comerciales reivindicadas. Así, entre la diversidad de objetivos susceptibles de ser asociados con "la" causa del CJ (entendida como relación de intercambio comercial Norte-Sur) aparecen argumentos que escapan a esa realidad geográfica específica y entran en consideración en las justificaciones de los entrevistados. Por ejemplo, la evaluación que hacen los promotores o consumidores del mérito que el beneficio de comprar productos del CJ tiene para ciertos productores (aquellos de países del Sur) en relación con otros (aquellos de países del Norte) es un dato central para comprender cómo se estructuran los mandatos de elección relativos a este tipo de comercio.

Tanto del lado de los promotores como de los consumidores franceses, defender la necesidad de una relación Norte-Sur y/o de una relación Norte-Norte con productores merecedores o beneficiarios del CJ provoca controversias, tomas de posiciones ideológicas, elecciones morales, permitiendo comprender los límites del compromiso definido y asumido por los promotores así como defendido y deseado por los consumidores. Este aspecto, perceptible en la retórica de los promotores y las justificaciones de los consumidores tiene un lugar importante y contribuye a explicar los compromisos y limitaciones sobre el grado de legitimidad acordado al acto de compra justa como acto de consumo "comprometido" según se lo define en distintos trabajos académicos franceses (Dubuisson-Quellier 2009; Cochoy 2008; Ferrando y Puig, y Giamporcaro-Saunière 2005; Chessel y Cochoy 2004; Bigot 2003).

\section{Tipología simplificada de los sectores del CJ}

El estudio-expertise publicado en 2002 por la Ong Solagral (Solidarités Agricoles et Alimentaires) fue una propuesta de lectura tipológica por sectores del CJ a nivel europeo (Habbard, Lafarge, Peeters y Vergriette 2002). En él se distinguieron dos circuitos comerciales: el sector integrado y el sector certificado, y se identificaron las organizaciones de productores (OP) beneficiarias de ambos sectores. 
Esquema simplificado de los sectores del CJ

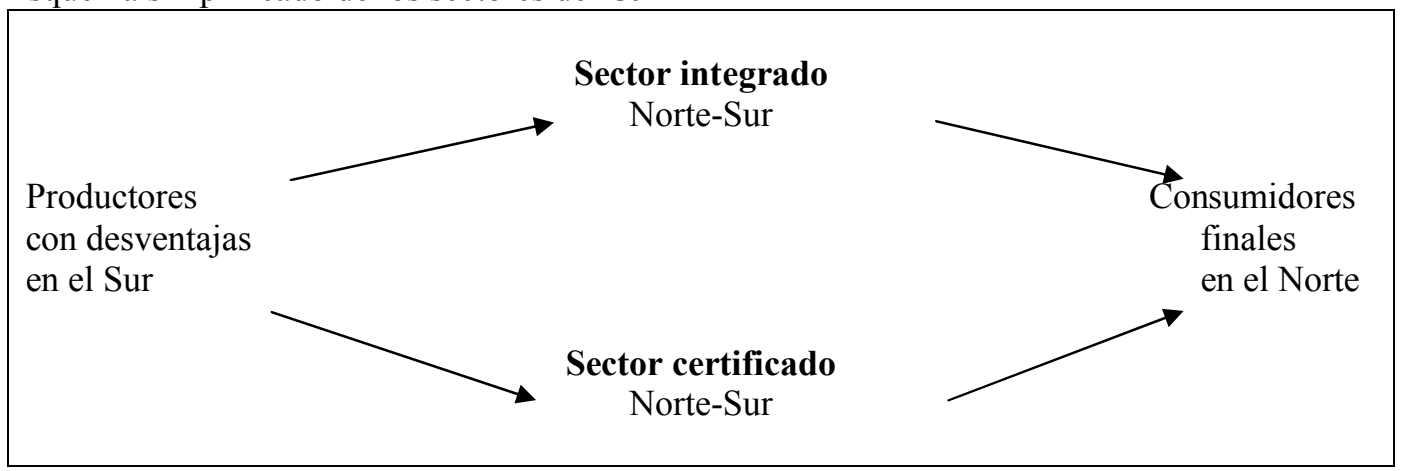

Fuente : Estudio Solagral, CIRAD, CICDA, CEDAC, 2002.

Las especificidades de cada sector fueron analizadas según los flujos comerciales y de información/comunicación que los caracterizan.

Por un lado, el sector integrado ("alternativo" o "especializado") es la forma histórica del CJ, iniciado en los años 50. Los tres actores que intervienen son:

- el importador ${ }^{4}$ compra directamente a las organizaciones de productores. Se caracteriza por "sobrepasar el rol de importador-exportador clásico". Más allá de la gestión comercial, los importadores establecen lazos de cooperación con las organizaciones de productores (bajo la forma de apoyo técnico, pre-financiamiento, durabilidad de la relación) y participan en la sensibilización de los consumidores al $\mathrm{CJ}$, gestionando y financiando campañas de promoción;

- las Tiendas del mundo revenden esos productos a los consumidores. Son "generalmente pequeñas superficies comerciales de estatus asociativo, donde los recursos humanos surgen del voluntariado". Están comúnmente afiliadas a una federación nacional. Más allá de la venta, son el relevo a nivel local de las campañas de sensibilización coordinadas por las federaciones que se centran en diferentes tipos de actividades (exposiciones, reuniones de información y programas de educación o formación);

- y las federaciones nacionales de tiendas aseguran, entre otras acciones, la promoción del CJ y llevan adelante acciones de plaidoyer respecto de las instituciones gubernamentales.

Todos son reconocidos como actores especializados en el seno del movimiento y se los llama en su conjunto Organizaciones del CJ $\left(\mathrm{OCJ}^{5}\right)$, (Habbard, Lafarge, Peeters y Vergriette 2002: 10).

\footnotetext{
${ }^{4}$ Se trata de centrales de compra especializadas que trabajan con varios tipos de redes de distribución: tiendas del mundo, venta por correspondencia o por internet.

${ }^{5}$ En inglés el equivalente de esta denominación es: Alternative Trade Organisation. En francés es: Organisation du Commerce Équitable.
} 
El estudio define al sector según seis características:

1- El tipo de aplicación de los principios del CJ (ya sea un estatuto, un manual de procedimiento, o un código de conducta) releva de un compromiso voluntario y de autodeclaración (por oposición al lazo contractual y a la certificación por una tercera parte).

2- El estatus a priori asociativo o cooperativo de las OCJ con una perspectiva militante está apoyado casi exclusivamente en el voluntariado (ya sean vendedores en las tiendas o expertos profesionales que realizan misiones de evaluación de las organizaciones de productores).

3- La especificidad de los productos comercializados es su baja estandarización (relación calidad/tendencia del mercado del Norte).

4- Existe una proporción más elevada de productos terminados no-alimentarios (artesanía, arte decorativo, textil) con respecto a los alimentarios (que más allá del embalaje, para algunos casos, pueden conocer una fabricación externalizada).

5- Los volúmenes de intercambio bajos y los costos fijos de comercialización (excepto el transporte) son menores gracias también a los costos no contabilizados (horas de trabajo no remunerados).

6- La jerarquización de las tres actividades principales de los actores involucrados (venta, sensibilización, plaidoyer) es muy variable en el seno de las estructuras según el grado de profesionalización y sus capacidades institucionales.

Fuente : Estudio Solagral, CIRAD, CICDA, CEDAC, 2002. Traducción propia.

Por el otro, el sector certificado aparece como una forma nueva del CJ hacia fines de los años 80. La creación del sello Max Havelaar en los Países Bajos, en 1988, marca el inicio de su desarrollo. Según el estudio, sólo el organismo de certificación (cada país tiene el suyo ${ }^{6}$ ) puede ser reconocido como una Organización del CJ, ya que los otros intervinientes (importadores, transformadores, distribuidores) sólo tienen una parte de sus actividades comprometidas en el sistema (Habbard, Lafarge, Peeters y Vergriette 2002: 16).

La lógica comercial específica del sector certificado (donde se originan las principales controversias en el seno del movimiento) se caracteriza por buscar promover el crecimiento del sello en los países del Norte, para alcanzar mayor salida comercial y beneficiar a los productores del Sur, con el fin de incitar a los distribuidores del circuito convencional (la gran distribución) a referenciar productos con el sello.

Los promotores de este sector desarrollan dos estrategias para ejercer presión sobre el sector de la distribución convencional. Por un lado, buscan multiplicar el número y el peso de los importadores/transformadores que utilicen el sello. Por el otro, apuestan a aumentar la notoriedad del sello respecto de los consumidores. La primera estrategia es la más difícil de llevar adelante porque la posición de los pequeños operadores especializados en el mercado en general es desventajosa respecto de las multinacionales. La segunda estrategia parece ser más accesible y eficaz para los certificadores ya que pueden valerse de las herramientas del marketing tradicional (financiando estudios/sondeos, incentivando las relaciones públicas) y llegar a externalizar estas actividades contratando a consultoras en comunicación. Esta estrategia de promoción se encuentra en las antípodas de la lógica del sector integrado mencionado.

\footnotetext{
${ }^{6}$ En Francia, Max Havelaar France cumple esta función desde 1992.
} 
Las características que definen al sector certificado son:

1- Posibilidad que una empresa convencional comercialice productos respetando los principios del CJ codificados en criterios estandarizados, lo que abre la venta a los circuitos convencionales de distribución (supermercados e hipermercados).

2- El tipo de lazo entre los intervinientes es contractual entre el poseedor de la licencia del sello (el importador/transformador del sector convencional) y su propietario (el certificador), contrariamente al sector integrado basado en un lazo institucional (solidaridad/militantismo).

3- Los términos contractuales que encuadran la atribución del sello (bajo la condición del pago de un canon al organismo certificador) se apoyan globalmente sobre dos principios: la adopción de modalidades comerciales específicas (donde la fijación del precio de compra es el más relevante) y el aprovisionamiento a partir de organizaciones de productores previamente certificados por el certificador.

4- La certificación vía el sello se refiere sólo al producto comprado a las organizaciones de productores y no del sector o sobre todos los componentes del producto final vendido al consumidor (las eventuales fases de transformación de esos productos están bajo la única responsabilidad de la empresa certificada y no están cubiertas por el sistema de certificación, en otros términos, la responsabilidad social de la empresa (RSE) no está certificada por el sello).

5- El organismo certificador, además de su rol certificador, juega también un rol de promotor del sello vía las campañas de sensibilización de los consumidores (con respecto a la gran distribución lo incitará, por ejemplo, a referenciar mejor los productos certificados).

6- La mayoría de los productos certificados son productos agroalimentarios de gran consumo.

Fuente : Estudio Solagral, CIRAD, CICDA, CEDAC, 2002. Traducción propia.

El estudio describe asimismo para el caso de las organizaciones de productores beneficiarias, la realidad social a la que pertenecen. Se trata de "grupos de poblaciones desfavorecidas, al margen del crecimiento y/o expuestos a la pobreza: pequeño campesinado, poblaciones urbanas en zonas insalubres, comunidades y minorías étnicas, mujeres vulnerables, hogares monoparentales, etc. Esos grupos así identificados se apoyan en diferentes formas de organización del trabajo, siguiendo la naturaleza y el lugar de producción: producción agrícola o artesanal, zonas rurales, urbanas o periurbanas, etc." (Habbard, Lafarge, Peeters y Vergriette 2002: 8). 
Los tres tipos de organización de productores beneficiarios son:

- Las cooperativas y las asociaciones de productores agrícolas (principalmente en los sectores del café y del cacao) y las grandes plantaciones (para el caso de los sectores del té y de la banana en particular);

- Las pequeñas y micro empresas, que son específicas de la artesanía, decoración, confección y textil;

- Las asociaciones y las ONG locales ${ }^{7}$.

Fuente : Estudio Solagral, CIRAD, CICDA, CEDAC, 2002. Traducción propia.

Esta tipología incluye organizaciones de productores situadas en países del Sur, principalmente de tres regiones: América Latina, África y Asia del Sur. El caso argentino ejemplifica cómo se inserta en el mercado mundial del CJ, un país del Sur, a través del sector certificado.

En Argentina la certificación de productos, utilizando el sello FLO-Cert ${ }^{8}$, surge en 2006 por iniciativa independiente de cooperativas, como la Cooperativa Vitivinifrutícola de La Rioja Ltda., que se orientan hacia segmentos de mercado específicos (como el orgánico, comercio justo) para obtener nuevos canales de comercialización para sus productos atraídos por el pago de precios diferenciales. Luego aparece una instancia institucional que nuclea y sistematiza las actividades del sector.

En 2009, la Fundación Fortalecer nace en el seno de la Federación Agraria Argentina (FAA) en los años 2000 como organización de capacitación y asistencia técnica para productores agropecuarios y comienza a interesarse por los principios del CJ en el marco de la ejecución de proyectos financiados por el Banco Interamericano de Desarrollo (BID) a través de la línea FOMIN (Fondo Multilateral de Inversiones). Este interés surge concretamente al término del proyecto sobre "Sistema de Facilitación de Acceso a Mercados Internacionales para Pequeños y Medianos Productores Rurales", donde los principios del CJ aparecen asociados con las normas de calidad incluidas en los planes de negocios. A partir de esta experiencia la Fundación Fortalecer propone otro proyecto al BID focalizado en el tema del CJ para el cual obtiene financiamiento dando origen al programa "Promoción de Sistemas Productivos Sustentables a través de Mercados del Comercio Justo" (Fortalecer 2013).

Sonia Solari ${ }^{9}$, directora ejecutiva de Fortalecer, señala que el propio BID-FOMIN les sugiere trabajar prioritariamente con el organismo de certificación internacional FLO-Cert para el caso de la certificación de productos destinados al comercio exterior. Fortalecer se vuelve entonces el representante del sello FLO-Cert en Argentina. Sin embargo, a nivel nacional, crea un sello propio llamado "Reconocimiento Nacional Comercio Justo", para certificar a productores y

\footnotetext{
${ }^{7}$ Este último tipo de organización beneficiaria del CJ es tomado en cuenta en el estudio porque según sus autores, esas organizaciones juegan un rol determinante en el lanzamiento de las redes del CJ en la medida en que ellas aportan un apoyo técnico o financiero a las OP con el fin de ayudarlos a cumplir con los criterios del CJ y la viabilidad económica. Ese apoyo intervine generalmente a partir del pedido y en colaboración con los importadores (para el caso de los sectores integrados) o de los organismos de certificación (para el caso de los sectores certificados): servicios de exportación, administración y contabilidad, formación y transferencia tecnológica, etc. (Habbard, Lafarge, Peeters y Vergriette 2002: 89).

${ }^{8}$ En 1997 nace la federación FLO (Fairtrade Labelling Organisation) que reagrupa las diferentes iniciativas de sellos del CJ en el mundo (Max Havelaar, TransFair o Fairtrade). En 2004 se crea la empresa de control y certificación FLO-Cert. A partir de entonces las actividades de apoyo a los productores y de certificación estarán disociadas al interior de FLO. FLO-Cert asegurará la certificación y el control de la aplicación de los estándares y pliegos de condiciones del sector por parte de las organizaciones de productores, los distribuidores y los importadores.

${ }^{9}$ Entrevista realizada en enero/2014.
} 
cooperativas que comercialicen sus productos en el mercado interno. En muchos casos las cooperativas involucradas van a obtener la doble certificación.

El caso argentino es un ejemplo de diversificación del sistema de certificación del CJ, regido por el tipo de mercado al que se destinan los productos, el mercado interno y el mercado externo. Coexisten dos lógicas de intercambio, Norte-Sur y Sur-Sur. Esta diferenciación tendrá un impacto en el proceso de estandarización de los criterios de certificación, alcanzando cierta flexibilidad para el caso de la certificación nacional de aquellos productos que no son objeto de demanda externa. El compromiso de la Fundación Fortalecer con FLO-Cert es respetar este criterio discrecional.

Basado en casos similares a la experiencia argentina existen investigaciones donde el análisis tipológico sobre las filiaciones ideológicas y las prácticas de los actores del CJ se complejiza, pasando de una lectura por sectores a una por polos, lo cual rompe con la visión geográfica exclusiva de la relación Norte-Sur con las poblaciones beneficiarias.

\section{Tipología compleja de los actores del CJ, por "sectores" y por "polos"}

Diferentes trabajos científicos en ciencias sociales definen tipológicamente al movimiento del CJ por sectores (por ejemplo Ronan Le Velly desde un enfoque socioeconómico) hasta plantearse la existencia de polos (por ejemplo Philippe Robert-Demontrond, en ciencias de la gestión).

Siguiendo un análisis socioeconómico, Ronan Le Velly distingue tres sectores del CJ: el sector directo, el sector integrado y el sector certificado. A partir de la metodología de la Nueva sociología económica ${ }^{10}$ el autor analiza para cada uno de ellos, las "condiciones de encastramiento estructural (estructuración de los sectores), cultural (justificaciones del establecimiento del CJ) e institucional formal (reglas y herramientas utilizadas para seleccionar los productores, fijar los precios de compra, inspirar la confianza del consumidor y distribuir los productos)", (2002: 37-53). A partir de este enfoque teórico que considera el carácter socialmente construido y variado de los mercados concretos, el autor propone describir las diferentes modalidades de funcionamiento que atraviesan al mercado del CJ (Le Velly 2009). A cada tipo de sector del CJ le corresponde un carácter sistémico de condiciones de encastramiento y una variedad de organización diferente.

${ }^{10}$ El autor cita como referentes los trabajos de Abolafia (1996); Biggart (1998); Callon (1998); Granovetter (1985) y Zelizer (1992; 2001). 


\begin{tabular}{|l|l|l|l|}
\hline \multicolumn{1}{|c|}{ Sector directo } & Sector integrado \\
\hline $\begin{array}{l}\text { Estructura } \\
\text { del } \\
\text { sector } \\
\text { Directo y }\end{array}$ \\
\hline $\begin{array}{l}\text { Razón de ser } \\
\text { del CJ }\end{array}$
\end{tabular}

Fuente: Ronan Le Velly 2006.

El sector directo se caracteriza por la importación directa de productos por las primeras Tiendas del mundo que luego van a llamarse boutiques Artisans du Monde ${ }^{11}$. Su estructuración comprende: la realización de pedidos de manera directa a los grupos de productores, el establecimiento de contactos privilegiados con ellos sin la aplicación de criterios formales de selección, la venta en espacios "militantes" (salida de las iglesias, manifestaciones tercermundistas, locales asociativos), una clientela militante convencida en los proyectos apoyados por las ventas, haciendo de sus compras un acto movilizado más por la simpatía o la solidaridad hacia los productores que motivado por la calidad de los productos.

El sector integrado es descripto por el autor como aquél que nació de una necesidad del movimiento Artisans du Monde de estructurarse con el propósito de "apoyar un mayor número de productores y sensibilizar a una clientela más vasta". La central de importación Solidar'Monde fue creada en el seno de este movimiento militante para reducir los costos de importación, gestionar mejor los stocks y diversificar la gama de productos comercializados. Las compras que antes se realizaban directamente a los productores se volvieron "intermediadas y centralizadas". La selección y el seguimiento de los grupos de productores fueron evolucionando hasta ser tomados a cargo por los miembros de una estructura internacional reuniendo once centrales de importación, la European Fair Trade Association (EFTA).

El sector certificado está representado en Francia por la asociación Max Havelaar France que da en concesión un sello y apoya la comercialización de productos certificados en los

\footnotetext{
${ }^{11}$ Artesanos del Mundo.
} 
supermercados. Desde un punto de vista estructural este sector se distingue del anterior porque su principal actor, la certificadora, no realiza ninguna operación de importación, transformación o comercialización. Dichas operaciones son "delegadas" según Le Velly. El autor confirma que este funcionamiento tuvo como consecuencia la puesta en competencia, por un lado, de los productores y, por el otro, de los concesionarios del sello. Los productores pueden obtener la certificación Fairtrade/Max Havelaar pero ello no implica que automáticamente vayan a encontrar compradores para sus producciones. Los concesionarios del sello se encuentran en competencia directa para lograr ser referenciados en los supermercados no sólo entre ellos sino también con las Marcas de distribuidores (MDD), o sea las propias marcas de los supermercados que acceden también a la certificación Fairtrade. Desarrollamos y analizamos este punto en la sección siguiente a partir de nuestro trabajo de campo.

Desde el enfoque en ciencias de la gestión, Philippe Robert-Demontrond construye una cartografía de posiciones ideológicas de los actores del CJ que da cuenta de la complejidad de polos que estructuran al movimiento (2008). Critica los análisis que describen la estructura del sistema económico justo siguiendo un "continuum entre dos polos, uno "militante", defensor de una práctica confidencial del CJ, y el otro "pragmático", apuntando al desarrollo masivo y profesionalizado del mercado", ya que dejan de lado otras posturas que promueven "privilegiar las vías de un desarrollo del CJ local (Robert-Demontrond y Joyeau 2010: 66). Su propuesta tipológica toma en cuenta dos categorías de actores. Por un lado, "los alter-mundialistas, detentores de otra economía del bien, para quienes el CJ permite integrar a productores marginalizados del sistema económico mundial y son favorables a la distribución de los productos en los supermercados". Por el otro, "los anti-mundialistas, detentores de una economía del lazo, para quienes el CJ permite salirse del sistema económico mundial, de las relaciones económicas liberales y del sistema capitalista, apelando al decrecimiento y al desarrollo local" (Robert-Demontrond y Joyeau 2010). 
Tipología por polos del comercio justo (Philippe Robert-Demontrond)

\begin{abstract}
En la misma perspectiva de regionalización del CJ que el polo 2 pero con la preocupación por un fuerte desarrollo económico, varias iniciativas apuntan a acercar los consumidores urbanos a los productores rurales.

Un ejemplo típico es la iniciativa Comercio Justo Méjico, en respuesta a la insatisfacción vivida por varios grupos de productores en cuanto a las normas y reglas de los sellos destinados a los mercados de exportación. Lanzado en el mercado interno, en 2002, este sello da así la posibilidad a los consumidores mejicanos de privilegiar la producción local y de comprometerse en una lógica de economía social y solidaria. La iniciativa concierne únicamente las organizaciones de productores (y no los asalariados de plantaciones).

Ej.: Comercio Justo México.
\end{abstract}

COMERCIO REGIONAL

\section{1- El sector directo "comercial" \\ 2- El sector directo "militante"}

Este polo reivindica la primacía de lo local como fundamento del lazo y el rechazo al acercamiento con actores convencionales de la distribución. Aquí, el CJ Sur-Norte trae problemas: transporte de las mercancías (condiciones de trabajo a bordo de los barcos, contaminaciones, etc.) y confinamiento de los PED (Países en vías de desarrollo) a un rol de productores de cultivos de renta (café, cacao, azúcar, banana, etc.) logrando preservar sólo algunos islotes de prosperidad.

El desarrollo de los mercados justos en circuitos cortos para los productos regionales debería ser promovido por ser una oferta juzgada más ecológica gracias a la proximidad, propiciando el desarrollo de nuevas solidaridades.

Contra toda idea de crecimiento de los volúmenes de venta, algunos suscriben a los llamados al "decrecimiento" e inscriben sus prácticas, antes que todo educativas, en una lógica de "simplicidad voluntaria" o de "noconsumo".

Ej.: Minga, Breizh Ha Reizh, IDEAS.

ECONOMIA DEL LAZO

\section{3- El sector certificado}

Estos actores constituyen el polo comercial; el CJ no puede realmente integrar a productores marginalizados del sistema económico mundial si no pueden asegurar volúmenes de venta consecuentes. De ahí el recurso de venta a los supermercados que de hecho lanzan sus propias marcas de productos justos. Este polo se basa en la certificación de sectores y el sello de productos.

Numerosos actores son sociedades con fines de lucro, justificando la búsqueda de beneficio.

Convenciones de redistribución de los dividendos son comúnmente establecidas entre los accionarios, especificando que la prioridad no está dada a su enriquecimiento sino a la reinversión de los beneficios en las actividades de la empresa. Pero el aspecto lucrativo puede prevalecer sobre otra

\section{4- El sector integrado}

Los actores de este polo histórico y militante consideran a la colaboración (el lazo) como un elemento esencial del CJ, atribuyéndole directamente a éste una vocación internacional en una perspectiva de cooperación de los pueblos a través del comercio. Mayormente especializados en la importación y comercialización de artesanías y productos alimentarios manufacturados, esas organizaciones de comercio alternativo promueven cadenas de aprovisionamiento con un alto grado de integración vertical; venden directamente a los consumidores en las tiendas al detalle (minoristas) que les pertenecen.

La iniciativa está esencialmente fundada en la confianza mutua de los actores y el respeto de los compromisos contractualizados en los estatutos comunes (carta asociativa).

Ej. : Artisans du Monde. 
consideración. Cada vez más actores (distribuidores o industriales) entran también en el mercado atraídos por el crecimiento y las perspectivas de beneficio económico, ganando al mismo tiempo en prestigio e imagen: Nestlé, McDonald's, Starbucks, etc. Ej. : Max Havelaar, Alter Eco, Lobodis.

COMERCIO INTERNACIONAL 
A través de los tres análisis tipológicos presentados (el estudio-expertise de la Ong Solagral; el análisis socioeconómico de Ronan Le Velly y el de ciencias de la gestión de RobertDemontrond) observamos cómo el CJ está atravesado por una estructuración compleja de relaciones sociales entre promotores, consumidores y productores. Como sistema comercial, se lo puede relacionar con diferentes sectores comerciales. Como movimiento social, puede analizarse siguiendo los distintos posicionamientos ideológicos de los actores sobre la manera de definirlo según la perspectiva que adopta cada sector.

En el espacio francés observamos, por ejemplo detrás de la definición del CJ, relaciones de fuerza entre dos colectivos de actores que buscaron desde el inicio dar legitimidad al CJ, la Plate-forme pour le commerce équitable ${ }^{12}$ (PFCE) y la red Minga. Por un lado, la PFCE (constituida en 1997) reconoce institucionalmente la definición del CJ adoptada en 2001 por cuatro estructuras internacionales del movimiento, la red $\mathrm{FINE}^{13}$, que adquiere a nivel mundial gran notoriedad.

"El comercio justo es una colaboración comercial, fundada en el diálogo, la transparencia y el respeto, donde el objetivo es alcanzar una mayor equidad en el comercio mundial. Contribuye al desarrollo sustentable ofreciendo mejores condiciones de intercambios, garantizando los derechos de los productores y de los trabajadores asalariados, particularmente los del Sur del planeta. Las organizaciones del CJ se comprometen activamente, con el apoyo de los consumidores, a apoyar los productores, sensibilizar la opinión pública y llevar adelante campañas en favor de cambios en las reglas y prácticas del comercio internacional convencional." (Fuente: European Fair Trade Association, Mémento du Commerce Équitable 2001, p. 26.).

Por el otro, los miembros de la red Minga ${ }^{14}$ (creada en 1999), se definen como estructuras profesionales que respetan un estatuto y adoptan un "texto de posicionamiento" elaborado en el marco de su "función de organización política", y avalan otra definición del CJ:

"Economía y Comercio justo: "acción de un sector comercial donde los principales operadores (producción, transformación, prestaciones, distribución mayorista y minorista) se comprometen a un máximo de equidad y de respeto entre ellos y el medioambiente. La definición "oficial" en Francia se limita a relaciones "Norte-Sur" y la equidad apunta sólo a un eslabón de la cadena, los productores (¿quién de los otros actores?)”. (Fuente: Minga, Manual de procedimiento 2009.).

En Francia, el proceso institucional para llegar a una definición "oficial" del CJ pasó por distintas etapas conflictivas con la intervención de la AFNOR (Agence Française de Normalisation $^{15}$ ) y del Estado (Diaz-Pedregal 2007: 159-166; Gateau 2007: 109-115). Este conflicto aparece explícitamente en este país, por su condición de importador, detentor del sello, pero sobre todo por ser consumidor de estos productos. En un país como la Argentina, de carácter preponderantemente productor, resulta menos probable, por el momento, que surja de

\footnotetext{
${ }^{12}$ Plataforma por el Comercio Justo.

${ }^{13}$ Creada en 1998, FINE es el anacronismo de las cuatro estructuras internacionales: FLO (Fairtrade Labelling Organizations International - El Organismo de Certificación del CJ) ; IFAT (International Federation for Alternative Trade - La Federación Internacional por el CJ), actualmente WFTO (World Fair Trade Organization - La Organización Mundial del CJ) ; NEWS! (Network of European World Shops - la Red de Tiendas del Mundo en Europa); EFTA (European Fair Trade Association - la Federación de Importadores Europeos).

${ }^{14}$ Creada por la sociedad cooperativa comercial Andines.

${ }^{15}$ En Argentina el organismo equivalente es el Instituto Argentino de Normalización y Certificación (IRAM).
} 
manera estructurada y/o institucionalizada un conflicto o controversia sobre la definición o la legitimidad de los circuitos de comercialización válidos para el CJ. Cuestiones como quién y cómo se concibe al $\mathrm{CJ}$ en Argentina no han dado lugar aún a una reivindicación precisa o relaciones de fuerza entre los actores involucrados en el proceso de integración al sistema. Su condición de país productor-exportador regido por el modelo de la certificación prevalece por sobre las divergencias ideológicas que aparecen en un país consumidor como Francia con una trayectoria y práctica militante respecto del modelo de comercialización o consumo justo a desarrollar.

Otra forma de identificar el origen de relaciones de fuerza conflictivas en torno a la concepción del CJ y su legitimidad, es posible analizarlo a través del circuito de comercialización que priorizan los actores según los sectores y/o polos de pertenencia dentro del movimiento.

\section{"Democratizar" la venta de productos en supermercados, un debate controvertido}

A nivel mundial, los promotores de la "democratización" de la venta de productos a través de los supermercados pertenecen al "sector certificado del polo comercial", retomando el esquema de Robert-Demontrond. La propia evolución histórica de este sector dentro del movimiento está íntimamente ligada con esta lógica comercial. Con el argumento de beneficiar a la mayor cantidad de productores, garantizándoles un aumento de sus volúmenes de exportación, este sector privilegió el comercio a través de este circuito de distribución convencional.

En Europa, como lo analiza Jean-Frédéric Lemay, "el segundo período de institucionalización del movimiento del CJ" (2007: 27-28) marca la entrada en escena de los supermercados como actor económico activo en la cadena de comercialización de los productos del CJ. Lo que caracteriza a este período es la aparición de la certificación. Este sistema nació en 1988 en los Países Bajos por iniciativa de la asociación Max Havelaar ${ }^{16}$ que crea el sello del mismo nombre. El principal interés de sus fundadores, el sacerdote obrero Frans van der Hoff y el economista Nico Roozen, era propiciar un cambio de escala en la comercialización del café proveniente de una cooperativa mejicana, UCIRI (Unión de Comunidades Indígenas de la Región del Istmo de Oaxaca), donde el sacerdote obrero trabajaba con los productores (Roozen y Van der Hoff 2002: 80). El proceso de certificación con el sello Max Havelaar se inició con el cafér ${ }^{17}$.

\section{Los defensores de la gran distribución. De la iniciativa holandesa...}

Apoyándose en su propia experiencia de terreno, los fundadores del sello se opusieron a la lógica histórica del CJ representada por las Tiendas del mundo al considerarla reducida a una escala de comercialización limitada. Uno de ellos justifica esta posición a partir del propio argumento del productor mejicano con el que había trabajado durante su estadía en Oaxaca, México, quien le había manifestado la necesidad de comercializar más volumen de café a través del circuito del CJ para beneficiarse aún más del "precio justo ${ }^{18 "}$ obtenido por su producción,

${ }^{16}$ Es el nombre del protagonista de una novela publicada en 1860 por el holandés Edouard Douwes Dekker (bajo el seudónimo de "Multatuli"). Este personaje fue el iniciador de una denuncia de opresión ejercida sobre los javaneses por la administración colonial holandesa. (Multatuli 1820-1887: 2003).

${ }^{17}$ Este producto es particular si consideramos su peso relativo en la comercialización mundial de materias primas, ya que es el segundo, en volumen, comercializado después del petróleo.

${ }^{18}$ Es el principal criterio específico que se le reconoce al CJ. Otros son la supresión de intermediarios en la cadena comercial, la inclusión de productores marginalizados del sistema y la sustentabilidad económica, social y ambiental de estos mismos actores.

La denominación "precio justo" pago a los productores responde a un doble objetivo según lo comunican sus promotores. Recubre, a la vez, un compromiso económico y moral en esa relación comercial. Implica el pago de un precio mínimo garantizado para evitar a los productores someterse a las fluctuaciones de precios del curso mundial de las materias primas, y el mejoramiento de sus calidades de vida en cuanto a sus necesidades de salud, habitacional, educación, etc. Es, en la práctica, el "precio de compra" de un bien 
superando el impacto "simbólico" que había tenido su venta a través de aquella red (2002: 99100).

Los representantes del sello Max Havelaar sostuvieron que el medio para salir de cierta confidencialidad en los intercambios comerciales de café justo era acercarse directamente a un actor económico capaz de responder a la ecuación "multiplicar el precio por el volumen", los supermercados. Nico Roozen explica cómo logró convencer a este actor de la oferta alimentaria y agroindustrial tradicional de incorporar estos productos, desplegando una estrategia de presión sobre los procesadores de café, industriales y distribuidores holandeses. La cual se aproxima a una lógica de lobbing clásica que reproducen a su vez los actores económicos especializados en el CJ o actores asociativos representantes del sello en cada país, como es el caso en Francia (2002: 102-124).

\section{.... la réplica comercial y asociativa en Francia}

El presidente de una empresa francesa pionera, especializada en la importación, transformación y distribución de productos del CJ como Alter Eco, retomará el mismo argumento de la certificadora, al justificar mayor volumen de venta a través los supermercados para garantizar la rentabilidad económica de la empresa y la salida comercial para los productores, permitiendo una relación importador-productor estable en el tiempo.

En la región de Pays de Loire (al noroeste de Francia) pudimos observar el rol activo de los militantes de la asociación NAPCE (Nantes Agir pour le Commerce Equitable Nord-Sud), representante del sello Max Havelaar France, en el proceso de incorporación de los supermercados de productos del CJ. En 1998, sus primeras acciones de sensibilización y promoción surgieron en el marco de una campaña ;Exija productos éticos! donde se solicitaba a adherentes o militantes de redes asociativas (inscriptas en el movimiento alter-mundialista o pertenecientes al mundo de la solidaridad internacional), firmar un máximo de petitorios (en forma de tarjetas postales) para ser enviados a los responsables de la gran distribución solicitando productos del CJ en las góndolas. El mensaje decía:

\section{Señor}

Como consumidor solidario con las poblaciones del Sur, me preocupo por la calidad social de los productos que compro. Los productos del comercio justo garantizan a los pequeños productores del Sur una remuneración acorde con su trabajo. Estoy dispuesto a privilegiar estos productos. Es por esta razón que le solicito introduzca (en su supermercado) el café justo garantizado por Max Havelaar, distribuido ya en 350 puntos de venta en Francia. Convencido que usted tomará en cuenta este pedido, lo saluda muy atentamente... (Fuente: NAPCE. Traducción propia).

La certificadora Max Havelaar France mostraba así su doble voluntad de sensibilizar al gran público respecto de los objetivos del CJ, pero sobre todo ejercer presión para introducir los productos en los supermercados, principalmente aquellos que llevasen el sello.

Las primeras acciones definidas por la asociación NAPCE consistían en hacer campaña para introducir el café justo en los supermercados y comercios, organizar stands de degustación en esos espacios, realizar charlas en escuelas y colegios para sensibilizar a niños y jóvenes al consumo de estos productos. La implicación de sus militantes en dichas acciones tenía como marco de justificación la necesidad de favorecer una "vulgarización ideológica y económica del CJ", buscando ampliar el acceso y la oferta de los productos en el espacio de mayor consumo promedio del ciudadano francés, los supermercados.

al productor o a su organización, y no el "precio a la compra" por el transformador o el consumidor (Diaz-Pedregal, 2007). 
Utilizando encuestas de satisfacción, apoyándose en redes personales y según la proximidad geográfica con supermercados del conglomerado de Nantes" "abiertos a la iniciativa", iban de puerta en puerta a los supermercados para obtener la autorización de realizar degustaciones e insistir sobre los distribuidores que referencien los productos.

\section{Los opositores de la gran distribución. De la crítica ideológica...}

Los promotores del "sector integrado del polo histórico y militante" (Fédération Artisans du Monde) y aquellos del "sector directo militante" (colectivo Minga) se mostraron desfavorables y abiertamente opuestos a ese proceso de cambio de escala comercial (a través de los supermercados) impulsado por los promotores del "sector certificado del polo comercial".

Adoptando una posición clara en el espacio francés contra la participación de la gran distribución en el mercado del $\mathrm{CJ}$, denunciaron sus prácticas económicas competitivas identificadas como injustas, tanto en los países del Sur como en los del Norte. Uno de sus representantes expresaba como principal crítica a la lógica de implantación de los supermercados en los países del Sur su "carácter monopólico en detrimento de las economías locales". Denunciaba asimismo como práctica competitiva no equitativa "la explotación, en el Sur, de una mano de obra barata, regida por una reglamentación del trabajo laxa y ventajosa para los hipermercados". Y en el Norte, "la opresión ejercida sobre los productores locales franceses en instancias de negociación de sus ventas", lo que les provocaba un problema ético.

Defendiendo un principio de coherencia interna, estos promotores opositores hicieron prevalecer su rechazo de "validar la compra justa a aquellos comerciantes guiados por los imperativos económicos y los mecanismos liberales de presión competitiva". Basándose en ese tipo de justificaciones los detractores de la gran distribución afirmaban hasta qué punto permitir el CJ por esta vía va en contra de una relación equitativa en los intercambios comerciales.

\section{.... a tiranteces al interior del movimiento}

Observamos así que las divergencias de puntos de vista sobre el tema de la gran distribución fueron fuente de tiranteces al interior de la red de actores del CJ en Francia.

Por un lado, una representante de la asociación de consumidores ASSECO-CFDT 44 retoma el argumento de la certificadora Max Havelaar y de aquellos distribuidores (como Alter Eco) que justifican la comercialización a través de los supermercados, mencionando que el $95 \%$ de los franceses realizan sus compras en este circuito y que por esa razón es ventajoso llegar a él.

Este mismo actor argumenta asimismo que lo que se vende a través de este circuito son productos transformados en el Norte. Entiende que es equiparable vender a través de una pequeña tienda especializada o del supermercado por el carácter de materia prima de los productos comercializados en el CJ, como el café o el algodón, lo que hace, según él, que el beneficio del sistema recaiga en los países productores del Sur. Situación cuestionada por los sectores opositores, mencionados más arriba, que critican en términos macroeconómicos las condiciones de intercambio comercial a nivel mundial, donde la plusvalía de la transformación de esos productos se realiza en los países del Norte.

Estas tensiones se expresan y las observamos en espacios institucionales como el Institut National de la Consommation ${ }^{20}$ (INC), donde los actores de ambos sectores renuevan permanentemente el desafío de encontrar una armonía en el discurso sobre los fundamentos y

${ }^{19}$ Ciudad cabecera de la región de estudio Pays de Loire, Francia.

${ }^{20}$ Instituto Nacional del Consumo. 
principios del CJ para garantizar al consumidor una coherencia sobre las prácticas propias del movimiento.

Sin embargo, la venta en los supermercados tuvo consecuencias económicas negativas para algunos actores con la aparición de marcas "propias", Marcas de distribuidores (MDD) como se llama a las líneas de productos con packaging propio Carrefour, Champion, Leclerc (supermercados franceses). Estas marcas al acceder a la certificación Max Havelaar entraron en competencia con las marcas pioneras del CJ (que hoy se identifican como Marcas especializadas), sufriendo éstas últimas el efecto "vulgarización" de los productos certificados con el mismo sello.

Una de las situaciones adversas señaladas por los representantes de las Marcas especializadas es el deber asumir la contradicción de ser a la vez proveedores del supermercado y competidor directo de su propia marca (MDD). Otra tiene que ver con la confianza del cliente que recae en el sello y no en la marca. Ello trae como consecuencia el aumento de la probabilidad que el consumidor haga una amalgama en la identificación de marcas, sin distinguir las especializadas respecto de las MDD. Por ejemplo, frente a un paquete de café de la marca MDD Agir ensemble $^{21}$ del supermercado Carrefour y un paquete de la Marca especializada Lobodis ${ }^{22}$, los dos con el sello Max Havelaar, el consumidor no puede hacer la diferencia entre las lógicas de trabajo desarrolladas en un caso y en otro. Sin embargo, los niveles de inversión o el tipo de relación establecido con los productores no son los mismos, pero ello no se refleja en las marcas. La presencia del sello garantiza de manera equivalente el respeto de los principios del CJ. Este hecho desventajoso para las Marcas especializadas, adicionado a la baja elasticidad de los precios que pueden ser practicados por ellas, tendrá un impacto directo y desfavorable en la capacidad de crecimiento económico de las empresas pioneras del CJ.

“[...] El consumidor tiene la tendencia de mirar primero el precio del producto y asociarlo al logo Max Havelaar, entonces se dice: "mientras sea Max Havelaar está bien". No se va a preguntar mucho sobre el perfil de la empresa que vende el café, la marca y lo que hay detrás. Primero mira el precio. Nosotros no podemos ser más competitivos, no es posible, es un poco complicado porque estamos en una relación donde los supermercados son a la vez nuestros clientes pero también nuestros competidores. Entonces, tienen todas las cartas en la mano y nosotros en términos de negociación tenemos dificultades [...] vendemos cada vez menos. Aquellos que participan del crecimiento del CJ hoy día [...] son las MDD [Marcas de distribuidores]. El CJ hoy crece gracias a ellas, que son imbatibles a nivel de los precios. Pensamos que ello pone un poco en riesgo los fundamentos [del CJ], a Lobodis como empresa." (Conferencia de Damien François, responsable de relaciones con los productores, Lobodis, Nantes, mayo 2009).

La crítica o el reproche que estos actores realizan a la certificadora de otorgar el sello a las MDD se entiende porque uniformiza frente a los consumidores, bajo una misma apelación, las condiciones que garantizan el sistema del CJ. La estrategia que desarrollan para superar esta dificultad es difundir durante las campañas de promoción el tipo de relación que establecen con los productores, buscando diferenciarse de los supermercados. Su intención es dar visibilidad a una relación "tipo", según los principios del CJ, entre un distribuidor especializado del Norte y una cooperativa de pequeños productores del Sur, mostrando a los consumidores las dificultades

\footnotetext{
${ }^{21}$ Actuar juntos.

${ }^{22}$ La sociedad SAS Lobodis creada en 1988 en Quintin (ciudad de la región de Bretagne) por Olivier Bernadas fue la primera empresa francesa en importar, realizar la torrefacción y comercializar cafés de la variedad pura arábiga a través del CJ.
} 
y ventajas de establecer el vínculo. Damien François, de la empresa especializada Lobodis, lo ejemplifica:

"En Bolivia trabajamos con 6 cooperativas que reagrupan cada una aproximadamente entre 100 y 200 productores. Comparativamente con Perú, donde trabajamos con $C E N F R O C A F E^{23}$, una cooperativa que reagrupa cerca de 2.000 productores, se trata de otra escala y otro tipo de relación. [En Bolivia instalamos] una antena local [BIB Lobodis] que represente a la empresa para facilitar nuestras importaciones, los aspectos logísticos, contractuales, financieros, etc., brindar ayuda, apoyar las cooperativas en esta gestión y garantizar el aprovisionamiento también, porque no es seguro que funcione, sobre todo al principio. [...] Al inicio tenía una función principalmente comercial, sobre todo garantizar los contratos, [pero de ella] nacieron otras [...] de acompañamiento de las cooperativas. [...] El marco de la relación justa va más allá de la sola relación comercial. [...] Deseamos expandir este tipo de intervención pero es una cuestión de recursos y mercados, quiere decir que cuanto más funcionen nuestros productos, los mercados se expandirán aún más y podremos realizar más ese tipo de intervención [...]." (Conferencia, Nantes, mayo 2009).

Un representante del sello rescata y valora el trabajo diferenciado que realiza el distribuidor especializado que tiene un contacto directo con el productor, a quién califica de empresario "cien por ciento CJ". Reconoce que el trabajo de una MDD no es el mismo que el de una empresa especializada. Sin embargo, el distribuidor especializado tiene un sentimiento de competencia desleal frente al supermercado cuando la certificadora otorga el mismo sello a ambas marcas. Sobre todo cuando el sello es también concesionado por grandes multinacionales. Esta situación es cuestionada y el representante de la certificadora encuentra difícilmente la justificación para diferenciar el trabajo de unos y otros. Jean-Pierre Doussin, vicepresidente de Max Havelaar France, explica:

"[...] Se les va a exigir, y será cada vez más, que el distribuidor [supermercado] que ha decidido vender productos bajo su marca tenga una relación directa con los productores. Existe por ejemplo Starbucks que de cierta manera es una MDD [...]. En este caso la certificadora $[F L O-C e r t]$ le impuso una relación directa con los productores, de no pasar más por los intermediarios ya que son los que [deciden sobre todo] en el mercado del café, ya sea orgánico o justo, a causa de su posición de fuerza, de su conocimiento del sector. A término, las MDD manejan los hilos en alguna medida del mercado. Imponerles tener esa relación directa con el productor no los llevará nunca a realizar el trabajo que ustedes hacen y que están describiendo. En el seno de FLO-Cert hay una unidad que se interesa específicamente en aquellos actores que hacen ese tipo de trabajo para buscar valorizarlo. [...] Comunicar sobre lo que ustedes hacen por ejemplo en Bolivia [es importante]. Pienso que existe un montón de consumidores que estarían muy interesados en saberlo y que comprarían su café en vez de un café mucho más anónimo de la marca Auchan o Carrefour." (Conferencia, Nantes, mayo 2009).

Esta solución preconizada por el representante del organismo certificador no le satisface al representante de Lobodis que reclama igualmente una implicancia mayor de la certificadora, previa al otorgamiento del sello, a través de pliegos de condiciones más estrictos para la obtención de la certificación por parte de las marcas de distribuidores clásicos, no especializados.

Esta situación de competencia entre las MDD y las Marcas especializadas en el mercado francés se inicia en el año 2008 aunque la comercialización de productos certificados CJ a través de los

${ }^{23}$ Central Fronteriza del Norte de Cafetaleros. 
supermercados haya comenzado diez años antes. El representante de la certificadora si bien reconoce que esta cohabitación de marcas ha "complicado" la situación de las pequeñas y medianas distribuidoras especializadas, según él, ello se ve compensado por el incremento del consumo en general de productos del CJ. Reafirma su postura diciendo que "los productos del CJ no deben ser sólo [consumidos por] personas que tienen los recursos para comprarlos, que hay que democratizarlos, lo que explica esta coexistencia [de marcas] que debemos organizar y no condenar a una y glorificar a la otra".

Por su parte, el representante de la empresa especializada defiende su postura crítica argumentando que la estrategia de marketing de informar a los consumidores más y mejor sobre las prácticas específicas que llevan a cabo, no sólo les implica más costos sino que no soluciona en nada el riesgo de desviaciones que las MDD representan para el CJ.

"A fuerza de querer democratizar al sector van a entrar cada vez más actores convencionales o dominantes en el mercado, sobre todo en el caso del café [...]. Se va a validar la presencia de traders, exportadores, importadores, todos comerciantes convencionales que son cuatro o cinco grandes empresas en el mundo, que concentran el $60 \%$ de los intercambios internacionales de café y que de una manera u otra sus filiales entran en el mercado del CJ o del orgánico. Ellos son ineludibles si se quiere hacer volumen y democratizar la venta. Como en el caso de las MDD que van a hacer sus cafés terciarizando la torrefacción, si Lobodis no vende más bajo su marca, quizás un día vamos a estar obligados, para asumir los gastos, por razones de rentabilidad, de hacer el café para Carrefour pero en ese caso ya no tendrá ningún interés [el $\mathrm{CJ}$ ]. El riesgo de dejar entrar en el sistema a ese tipo de actores es, según entendemos por el momento, si las reglas se mantienen, el de banalizar completamente al CJ, banalizar el sentido de lo justo y de hecho perder todos los objetivos que se suman al precio y a la prima ${ }^{24}$ [para el desarrollo de los productores]. A partir del momento en que [el CJ] se vuelva un nicho y una apelación discutida por los traders, el productor no tendrá prácticamente más nada que decir, su relación va a ser sólo con el trader que corre el riesgo de ser un poco más feroz. Y de hecho uno de los objetivos mayores del CJ que se llama el empowerment, o sea la emancipación y la toma del poder de las organizaciones [de productores] corre el riesgo de ser fuertemente cuestionada por la intervención de todos los actores convencionales y dominantes." (Damien François, idem).

El malestar provocado por esta política comercial de la certificadora surge claramente en esta empresa (Lobodis) que no duda en resaltar y poner sobre la mesa de debate las causas de un eminente estrangulamiento del sector si las reglas de certificación no cambian.

La certificadora reconoce el riesgo y pone por delante los esfuerzos realizados por FLO-Cert para que una multinacional como Starbucks (que comercializa una gama de café certificada CJ) sea obligada a realizar un contacto directo con los productores (acostumbrada a pasar por los grandes grupos de traders para importar) para poder acceder a la certificación. El compromiso exigido por el certificador a ese gran grupo económico, de no pasar más por los intermediarios, no será suficiente como única cláusula para evitar la desaparición de una empresa como Lobodis. Habrá que tomar en cuenta el tamaño de esas empresas especializadas para que no se

\footnotetext{
${ }^{24}$ Es una práctica económica desarrollada por los promotores del "sector certificador del polo comercial". Forma parte de los estándares fijados en el sistema de certificación internacional elaborado por FLO (Fairtrade Labelling Organizations International). Los productores reciben además del precio mínimo indicado en los estándares de los productos o el precio correspondiente al curso mundial si éste es superior, una prima para el desarrollo (según los productos varía del 8 al 30\% del precio mínimo). Ésta debe "ser utilizada únicamente para satisfacer necesidades colectivas, o para el refuerzo de la capacidad de los miembros de la organización." (Doussin, 2009: 65).
} 
vuelvan "solubles" en la configuración comercial competitiva desventajosa a la que son expuestas.

\section{A modo de conclusión}

Retomando los pasos del proceso de legitimación en Francia del circuito de comercialización de productos del CJ a través de los supermercados, que coincide con la propia historia de constitución del sector certificado dentro del movimiento a nivel mundial, hemos caracterizado los elementos de una controversia que se ha generado entre los defensores de la venta de productos en el seno del mercado liberal y aquellos que se opusieron ideológicamente a esta práctica colocándose en sus antípodas, denunciando su carácter inequitativo.

Pudimos identificar las consecuencias de las tiranteces que esta controversia provoca en el plano de las relaciones de fuerza entre los promotores franceses, incluyendo las asociaciones de consumidores. A través del ejemplo de la asociación de consumidores ASSECO-CFDT 44 pudimos observar cómo este tipo de organización se vuelve partidaria de un modelo de consumo justo, aquél que cauciona la compra en los supermercados ya que retoma el argumento de los promotores del "sector certificado del polo comercial". Lo que produce un freno durante las campañas promocionales para dirigirse a los consumidores siguiendo un mismo y solo mensaje compartido con los promotores del "sector integrado del polo histórico y militante", según la caracterización tipológica del movimiento desarrollada.

La contracara de esta lógica de comercialización ha podido ser detectada en el seno mismo del sector certificado. El promotor especializado Lobodis y militantes de NAPCE, al mismo tiempo que son parte integrante de este sector representado especialmente por el sello Max Havelaar France, no se identifican con algunas decisiones comerciales surgidas en el marco de la certificación. Por un lado, los promotores especializados sienten una competencia desleal respecto de la gran distribución y, por el otro, algunos militantes temen que la certificación de ciertos productos responda a un proceder ilegítimo. El objetivo económico y comercial que lleva adelante o representa el "sector certificado del polo comercial", en el origen motivado por la idea de una "democratización" en cuanto a un acceso masivo a la compra de productos justos en los supermercados, termina por no ser compartido por todos los promotores de este sector. Pudimos constatar aquí una ruptura o una competencia entre los actores de un mismo sector cuando la certificadora Max Havelaar France comenzó a otorgar el sello a las marcas "propias" de los supermercados (MDD).

El trabajo que debe asumir el movimiento del CJ, en Francia apoyado como lo vimos por el Institut National de la Consommation (INC), es de volver a dar confianza al consumidor. Para ello es necesario buscar un nuevo consenso alrededor de los principios fundadores del CJ y lo que representa el consumir de forma comprometida estos productos. La creación en abril de 2010 de la Commission Nationale du Commerce Équitable ${ }^{25}$ (CNCE) en ese país se presentó como una tentativa de resolución de esas divergencias en el espacio francés. En ese marco, cuestiones referidas a ¿cómo comunicar en prioridad sobre el impacto del CJ en los productores?, alimentó el debate en el seno del movimiento. Enfocarse en ese tema, comunicar valorizando el lazo de cooperación con los productores, es una estrategia estudiada por los distribuidores especializados franceses para escapar a la crisis de crecimiento económico que los afecta desde 2007-2008. Esta estrategia comercial es propiciada, como lo vimos, por el organismo de certificación estando él mismo asociado a esta nueva configuración comercial del mercado justo con la aparición de las Marcas de distribuidores (MDD) porque él certifica también a esas marcas.

\footnotetext{
${ }^{25}$ Comisión Nacional del Comercio Justo.
} 
La credibilidad del sistema se pone juego en esos debates observados al interior del movimiento, sin embargo a priori el consumidor francés esto no lo percibe. Surge la pregunta, ¿cómo puede entonces ejercer en esas condiciones una elección responsable con su compra? Mucho antes que las MDD lancen sus marcas de productos certificados con el sello Max Havelaar, la falta de transparencia pudo ser señalada por el consumidor militante (aquel que milita en una asociación vinculada al CJ), como una consecuencia directa del surgimiento de sellos impulsados por los propios supermercados. En ese momento la desconfianza se depositaba en el hecho que "Carrefour había creado la filière de A a Z del CJ. Iba a buscar la materia prima y creaba su propio sistema de certificación, ningún inspector externo podía decir algo, ellos decidían y en última instancia podían comprar cualquier café y decir que era CJ". La única garantía que tenían era "Carrefour nos dice". Con la certificación Max Havelaar de las marcas MDD, entre ellas la de Carrefour, esta situación cambió. Sin embargo, la oposición del consumidor militante a este tipo de comercialización persiste aunque reconozca un aumento en la confianza que el producto ofrecido en el supermercado respeta las normas del CJ por ser certificado. Por su parte, el consumidor advertido (aquel que identificamos como informado, avezado pero que no milita en ninguna asociación del CJ) también piensa como el militante que existe una "recuperación" (en el sentido de apropiación, de aprovechamiento comercial) del CJ por la gran distribución, lo cual pone de relieve otra dimensión, el control independiente del sector. El consumidor militante que adhiere a una organización del "sector directo militante", se alineará con la crítica de este sector sobre el sistema de certificación que califica de privado y no público, donde entra en discusión la falta de reconocimiento estatal del sello.

En Argentina este tipo de controversias no puede observarse en la medida que la comercialización de productos del CJ no ha alcanzado un grado masivo de distribución. Sin embargo, en las ferias de productos orgánicos, agroecológicos y del CJ, realizadas en espacios públicos (universidades, plazas, parques), donde se confina la venta de estos productos, aparecen apelaciones y sellos que el consumidor argentino no siempre está en condiciones de reconocer como propios de cada uno de esos circuitos. Esto indicaría la necesidad de profundizar el estudio de estas formas de comercialización y su relación con los sistemas de garantía que enmarcan las prácticas de consumo "comprometidas" o "responsables" como se las reconoce a las del CJ.

\section{Bibliografía}

BIGOT, R. (2003): "La consommation engagée: mode passagère ou nouvelle tendance de la consommation ?", Collection des rapports Crédoc, n 229 , septembre, Paris.

CHESSEL, M.-E. y COCHOY, F. (dir.), (2004): Marché et politique. Autour de la consommation engagée, Revue Sciences de la société, $\mathrm{n}^{\mathrm{o}}$ 62, Presses universitaires du Mirail, Toulouse.

COCHOY, F. (2008): "Faut-il abandonner la politique aux marchés ? Réflexions autour de la consommation engagée", Revue française de socio-économie, $\mathrm{n}^{\circ}$ 1, pp. 107-129.

DIAZ-PEDREGAL, V. (2007): Le commerce équitable dans la France contemporaine. Idéologies et pratiques, L'Harmattan, coll. Logiques sociales, Paris.

DOUSSIN, J.-P. (2009): Le commerce équitable, PUF, coll. Que sais-je ?, Paris.

DUBUISSON-QUELLIER, S. (2009): La consommation engagée, Les presses de Sciences Po, coll. Contester, Paris. 
EUROPEAN FAIR TRADE ASSOCIATION (2001): Mémento du Commerce Équitable: les enjeux du nouveau millénaire, 2001-2003.

http://www.european-fair-trade-association.org/efta/Doc/yb01-fr.pdf

FERRANDO Y PUIG, J., GIAMPORCARO-SAUNIERE, S. (et al.), (2005): Pour une "autre" consommation. Sens et émergence d'une consommation politique, L'Harmattan, coll. Dossiers Sciences Humaines et Sociales, Paris.

FUNDACIÓN FORTALECER (2013): Comercio justo: una alternativa de producción sustentable y orientada al beneficio social de los trabajadores. Experiencias de productores y organizaciones que implementaron los principios del Comercio Justo en Argentina, Fundación Fortalecer, Buenos Aires.

GATEAU, M. (2007): "Les militants du commerce équitable. Analyse localisée de l'engagement dans deux associations", Tesis de doctorado en Sociología, director: Jean-Pierre Sylvestre, Université de Bourgogne, Dijon, Francia.

HABBARD, P.; LAFARGE, L.; PEETERS, A. y VERGRIETTE, B. (2002): "État des lieux et enjeux du changement d'échelle du commerce équitable - Typologie des filières, marchés de consommation, gouvernance internationale et cohérence globale du commerce équitable", Estudio Solagral, CIRAD, CICDA, CEDAC, octubre.

LEMAY, J.-F. (2007): "Commerce équitable: vers des chantiers de recherche ancrés dans la pratique", Les cahiers de la CRDSS, ÉSG UQAM, coll. Recherche, n 9.

LEMAY, J.-F. (2007): "Mouvements sociaux transnationaux: le partenariat de deux organisations du commerce équitable en France et au Pérou", Tesis de doctorado en Antropología, Université de Laval, Québec, Canadá.

LE VELLY, R. (2002): "La notion d'encastrement : une sociologie des échanges marchands", Sociologie du travail, 44 (1), pp. 37-53.

LE VELLY, R. (2004): "Sociologie du marché - Le commerce équitable: des échanges marchands contre le marché et dans le marché", Tesis de doctorado en Sociología, director: Alain Caillé, Université de Nantes, Nantes, Francia.

LE VELLY, R. (2006), "Le commerce équitable: des échanges marchands contre et dans le marché”, Revue Française de sociologie, 47-2, pp. 319-340.

LE VELLY, R. (2009): "Filières. La variété des marchés", Courrier de la planète, $\mathrm{n}^{\circ} 87$, 03/2009, p. 15.

MINGA (2009): Cahier des Charges Minga (Manual de procedimiento del colectivo francés Minga): http://www.minga.net/IMG/pdf/Cahier_des_Charges_de_Minga_2009.pdf.

MULTATULI (1820-1887), (2003): Max Havelaar ou les Ventes de café de la compagnie commerciale des Pays-Bas, trad. Philippe Noble, Actes Sud, coll. Babel, Arles.

PARODI, G. (2011): “Acheter pour s'engager. La figure du consom'acteur du commerce équitable", Tesis de doctorado en Sociología, directora: Véronique Guienne, realizada y defendida en la Université de Nantes, Nantes, Francia. 
ROBERT-DEMONTROND, PH. (2008): "Entre ictus, rires et rictus : les avenirs du commerce équitable", ponencia Coloquio FTIS 2008, $3^{\text {eme }}$ Colloque international sur le commerce équitable, "Nouvelles dimensions du commerce équitable : implications et défis", organizado por el CIRAD, CRI-IEDES Ile de France y FairNESS, Montpellier, France, 14-15 y 16 de mayo.

ROBERT-DEMONTROND, PH. y JOYEAU, A. (2010): "Les acteurs de l'offre et les consommateurs du commerce équitable. Entre économie du bien et économie du lien", in B.TURCOTTE M.-F. y HERVIEUX, CH. (dir.), Mettre en marché pour une cause. Commerce équitable, une comparaison internationale, Presses de l'Université de Québec, coll. Pratiques et politiques sociales et économiques, Québec.

ROOZEN, N. y VAN DER HOFF, F. (2002): L'aventure du commerce équitable. Une alternative à la mondialisation par les fondateurs de Max Havelaar, trad. Mireille Cohendy, Lattès, Paris. 